\title{
Pre-Kindergarten Teachers' Understanding and Perceptions of the Classroom Assessment Scoring System (CLASS)
}

\author{
Elizabeth Block, Mary Breaud, Shelby Cavalier, Lauren Guidry, Tiffany Papa, Mistie Perry \\ Nicholls State University, Thibodaux, Louisiana, USA \\ Email: tiffany.papa@nicholls.edu
}

How to cite this paper: Block, E., Breaud, M., Cavalier, S., Guidry, L., Papa, T., \& Perry, M. (2019). Pre-Kindergarten Teachers' Understanding and Perceptions of the Classroom Assessment Scoring System (CLASS). Creative Education, 10, 1988-1998. https://doi.org/10.4236/ce.2019.109145

Received: August 14, 2019

Accepted: September 13, 2019

Published: September 16, 2019

Copyright $\odot 2019$ by author(s) and Scientific Research Publishing Inc. This work is licensed under the Creative Commons Attribution International License (CC BY 4.0). http://creativecommons.org/licenses/by/4.0/

\begin{abstract}
This paper aims to explore pre-kindergarten teachers' perceptions of the level of support provided by school districts in the implementation of dimensions, examined by the Classroom Assessment Scoring System (CLASS). Survey and focus group data were gathered from 15 pre-kindergarten teachers within a Southern Louisiana school district. Survey data indicate that some teachers do not feel confident or knowledgeable enough to effectively implement CLASS domains. Through the focus group, teachers offered insightful feedback on the specific style of support and professional development opportunities that may assist in furthering the understanding of CLASS evaluation. Future research examining teachers' perceptions of their CLASS performance will aid in creating targeted and meaningful professional development support systems.
\end{abstract}

\section{Keywords}

Classroom Assessment Scoring System, CLASS, Positive Teacher-Child Interactions, Pre-Kindergarten Classroom, Teacher Perceptions

\section{Introduction}

Considered a best practice in early childhood education, young children's social and emotional development has become a focal point in the examination of classroom quality (Connors-Tadors \& Harorqitz, 2014; Martella \& Connors-Tadros, 2014) as reciprocal and engaging adult/child interactions within the pre-kindergarten classroom provide numerous opportunities for support of language and communication. Establishing a climate in which children feel confident to converse with teachers strengthens the complexity of children's language, leading to higher levels of critical thinking and problem-solving. 
Building upon these relationships as a basis for improving children's knowledge and understanding, the Classroom Assessment Scoring System (CLASS) assesses the early childhood classroom with regard to emotional and instructional quality through teacher-child interactions (Hambre, Goffin, \& Kraft-Sayre, 2009; Mashburn et al., 2008; Pianta, La Paro, \& Hamre, 2008). However, in order for the CLASS components to be effectively implemented, teachers should have a clear understanding of the specific components assessed by the instrument. This study explores pre-kindergarten teachers' perceptions of the level of support provided by school districts in the implementation of components examined by the CLASS tool.

\section{CLASS Domains and Dimensions}

Designed from other observational scales, the CLASS assessment tool measures multiple facets of interactions among teachers and children in three broad domains: 1) emotional support; 2) classroom organization; and 3) instructional support (Downer et al., 2010; Hambre et al., 2009; La Paro et al., 2014; Mashburn et al., 2008; Pianta, La Paro, \& Hamre, 2008).

The emotional support domain includes four specific behavior markers: 1) positive climate, 2) negative climate, 3) teacher sensitivity, and 4) student perspective (Pianta, La Paro, \& Hamre, 2008). A positive climate includes, but is not limited to, the formation of positive relationships between the teacher and student as well as relationships between students and their peers. Classrooms that score high in this domain indicate that the teacher and students enjoy warm, supportive relationships with each other (Pianta, La Paro, \& Hamre, 2008). A negative climate includes, but is not limited to, the observation of children who display frequent irritation and frustration in the form of bullying, teasing, and/or the use of humiliation or harsh punishment as a means of managing negative situations. Teacher sensitivity focuses on whether the teacher displays knowledge of her students' needs, both academically and socially. Teachers who demonstrate a high regard for student perspectives are flexible in incorporating student interests and ideas in their lessons, encouraging children to express these ideas and fostering independence and self-responsibility (Pianta, La Paro, \& Hamre, 2008).

The classroom organization domain includes three behavior markers: 1) behavior management; 2) productivity; and 3) instructional learning formats. Behavior management includes teachers' proactive behaviors in anticipating difficulties, establishing and consistently reinforcing clear expectations for students, reinforcing positive behavior, and redirecting negative behavior. Productivity includes observations of teacher preparation, brief transitions, continuous engagement, and effective implementation of classroom routines (Pianta, La Paro, \& Hamre, 2008).

The instructional support domain includes three behavioral markers: 1) concept development, 2) quality of feedback, and 3) language modeling. Concept development includes teachers actively facilitating student activities, using a va- 
riety of materials/modalities, and facilitating student engagement (Pianta, La Paro, \& Hamre, 2008). Quality of feedback involves consistent teacher feedback, both individually and in whole group activities. The teacher asks higher-order questions and encourages students to think critically and creatively while scaffolding the understanding of new knowledge through real-world connections. Language modeling is displayed when teachers are engaged in conversations and interactions with students throughout the school day, continuously modeling correct sentence structure and age-appropriate language constructs.

Each of these domains is broad and could include a wide array of interactions. Therefore, the CLASS tool includes a teacher rating scale that is widely utilized in determining children's outcomes, especially in the area of teacher-child relationships (Gaches \& Hill, 2017). It is also significant to understand that CLASS equates a student's current and future classroom competence with positive teacher-child relationships (Gaches \& Hill, 2017).

\section{CLASS and Teacher-Child Interactions}

Teacher-child interactions are the foundation on which each of the CLASS domains was developed. Teacher-child interactions help build relationships and student development in different areas that can improve student outcomes. Research indicates that teacher-child interactions and high-quality communication between teachers and their students are key in predicting positive academic outcomes (Gaches \& Hill, 2017). Supportive interactions, including effective behavior management strategies, predict increased positive behavior and greater student engagement in classroom activities (Hamre et al., 2013).

The CLASS tool assists teachers in creating awareness of teaching practices that promote positive interactions with their students every day. According to Reinking (2015), teacher-child interactions, which are intentionally planned by the teacher, promote learning of academic skills. Reinking found an increase in positive behaviors in students, as evidenced through teacher-child interactions associated with higher quality classrooms. Further, while Hamre et al. (2013) found that emotional support is associated with gains in standardized achievement scores, they concluded that the diversity of teacher interactions may be impossible to effectively assess using the CLASS tool. This underscores the teacher-child relationship and how the improvement of those interactions can affect students' outcomes.

\section{Teachers' Perceptions of CLASS}

While the CLASS tool is recognized as a gold-standard assessment in early childhood education, little research exists on teachers' perceptions of their expertise and efficacy in implementing the tool. Allar, Jones, and Bulger (2018) examined teachers' perceptions of how a specific implemented program impacted the quality of components examined by CLASS. Allar et al. (2018) solicited the perceptions of teachers on how a newly added obesity prevention pro- 
gram-I Am Moving, I Am Learning (IMIL) - positively impacted teaching efficacy. This exploratory study uniquely examines teachers' perceptions of how a new catalyst (IMIL) impacts the quality of the classroom environment as measured by CLASS. The authors call for further research to substantiate the teachers' perceptions, as there seems to be a significant lack of research on the direct examination of teachers' perceptions toward the amount of support and training of specific CLASS dimensions provided by school districts. This could have significant implications for teachers' understanding and interpretations of CLASS domains and dimensions which, in turn, could have a major impact on the quality of teaching practices.

\section{Methodology}

\subsection{Setting and Participants}

A school district in southern Louisiana was selected for this study due to geographic accessibility to the university at which the researchers were employed. The school district is rated A, ranks 4th in the state, supports over 22,000 students, and consists of 15 elementary schools serving children in pre-kindergarten through third grade. As CLASS is an early childhood assessment instrument, it is only implemented at the pre-kindergarten level in the public school system. Therefore, the authors narrowed the population of the study to pre-kindergarten teachers. The district employs 60 pre-kindergarten teachers and in order to achieve a representative sample of feedback from all schools, the authors randomly selected two certified pre-kindergarten teachers from each elementary school, resulting in a sample of 30 teachers. Based on a $50 \%$ response rate, data collected from 15 pre-kindergarten teachers were included in the study.

\subsection{Survey}

A pilot survey (see Appendix A) was developed to gather data on pre-kindergarten teachers' perceptions regarding implementation of the dimensions of CLASS. Based on the dearth of research on teachers' perceptions of CLASS, the authors developed survey questions around the personal constructs of confidence, efficacy and feelings of support in CLASS implementation. Questions were grouped in three domains including: 1) confidence and efficacy levels in implementing CLASS dimensions, 2) CLASS domains in which more support is needed, and 3) support and training concerning CLASS implementation provided by the school district. The seven-question survey was developed in a Google form format to facilitate efficient dissemination and the submission of anonymous responses. The survey comprised of three Likert responses, two short answer responses, and two multiple-choice responses.

\subsection{Procedure}

In February 2019, the pilot survey weblink was emailed to 30 pre-kindergarten 
teachers. The teachers were informed that there was no cost other than the time involved in survey completion, there was no benefit for completing the survey other than furthering the knowledge-base of the profession, and their responses would be confidential and anonymous. The teachers were given three weeks to complete the survey. Of the 30 teachers contacted, fifteen surveys were completed, with a response rate of $50 \%$.

After three weeks, a focus group was conducted with five of the pre-kindergarten teachers who participated in the survey. These teachers volunteered to participate in the focus group. Due to time and scheduling constraints, the focus group was conducted electronically via email. During the focus group, all members were given the same prompts including, but not limited to, 1) implementation of the CLASS tool in their classroom, 2) challenges in implementing the CLASS tool, and 3) supports that could be provided to improve knowledge in effectively implementing the CLASS tool. Focus group participants responded to their fellow participants and engaged in a reciprocal dialogue. Data collection was completed in March 2019 and survey and focus group data were aggregated into the tables below.

\section{Results}

Of the teachers surveyed, $73.3 \%$ felt somewhat confident in using the CLASS tool to enhance teaching practices and interactions in the classroom, whereas $26.6 \%$ did not feel so. When asked about the frequency with which they reference the Dimensions Guide of the CLASS tool, responses revealed that $7 \%$ of teachers responded always referred to it, $80 \%$ referred to it sometimes, and $13 \%$ never referred to the guide (see Figure 1).

When asked to self-identify the domain in which they need the most improvement, $86.7 \%$ of participants felt they required additional support regarding

Teacher's Perceived Confidence Utilizing CLASS Utilization of CLASS Dimension Guide

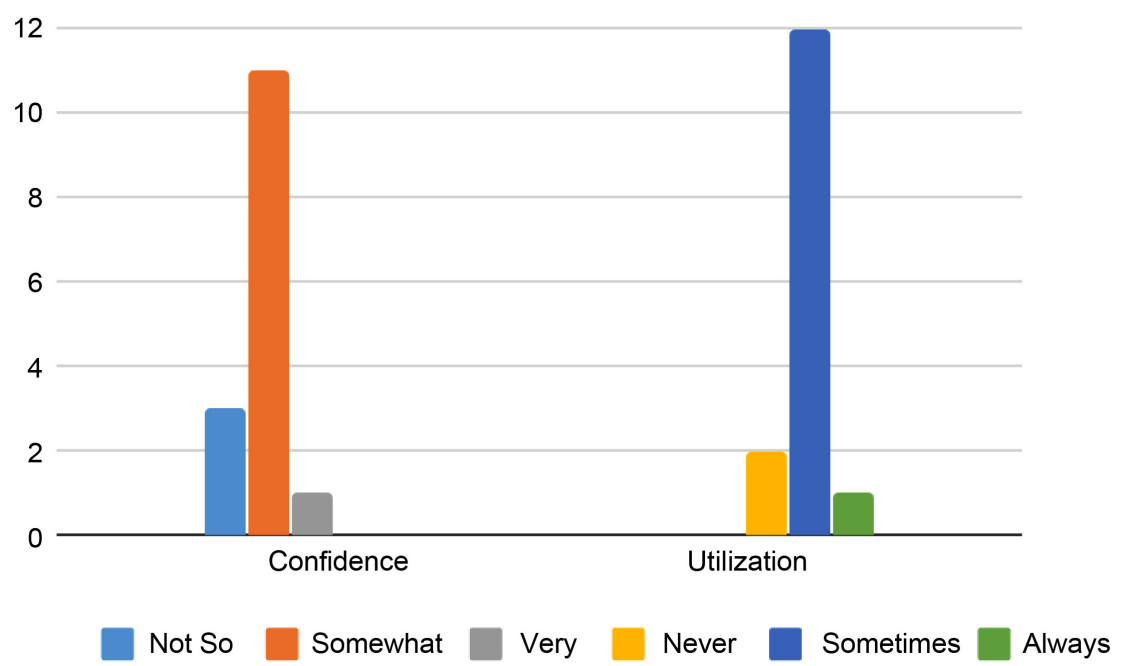

Figure 1. Frequency of reference to CLASS dimensions guide. 
Instructional Support, while 6.7\% focused equally on Emotional Support or Classroom Organization as areas for improvement (see Table 1).

When asked whether they received enough support to implement the CLASS, $40 \%$ of participants felt they did, while $33.3 \%$ felt they did not receive adequate support, and $26.7 \%$ were unsure (see Table 2 ).

\section{Focus Group Results}

When asked to identify key areas that support improved classroom interactions and teacher practices, $60 \%$ of the five focus group participants indicated additional professional development, $100 \%$ indicated additional individualized training, 40\% identified having additional resources for reference-such as shadowing, modeling, and role playing-would improve their knowledge of CLASS, and $20 \%$ indicated that professional development for para-professionals and peer modeling opportunities would contribute to a greater understanding and utilization of the CLASS instrument (see Table 3 ).

\section{Discussion}

With a small sample size of fifteen pre-kindergarten public school teachers participating in this survey, an adequate response rate was received, allowing the authors to draw tentative conclusions leading to future research opportunities. As with any formal assessment tool, the validity and reliability of the results obtained are contingent upon the instrument's implementation in the classroom setting. The survey data indicate that in this sample of pre-kindergarten teachers who have been in the field for four or more years, $73.3 \%$ felt somewhat confident in using the CLASS tool to help them with their teaching practices and interactions in the classroom, whereas $26.6 \%$ did not feel confident in using the CLASS tool.

This perceived confidence is relevant to the manner in which the instrument is implemented and sound interpretation of the outcomes. With the majority of the teachers feeling "confident" about the use of CLASS, a majority of teachers

Table 1. Teacher self-identified domains for improvement.

\begin{tabular}{ccc}
\hline Domain & Respondents & Percentage \\
\hline Emotional Support & 1 & 6.7 \\
Classroom Organization & 1 & 6.7 \\
Instructional Support & 13 & 86.7 \\
\hline
\end{tabular}

Table 2. Adequacy of levels of support in CLASS.

\begin{tabular}{ccc}
\hline Level of Support & Respondents & Percentage \\
\hline Receiving Adequate Support & 6 & 40 \\
Not Receiving Adequate Support & 5 & 33.3 \\
Unsure & 4 & 26.7 \\
\hline
\end{tabular}


Table 3. Supports desired by teachers to improve CLASS tool knowledge.

\begin{tabular}{ccc}
\hline Method of Support Desired & Results & Percentage \\
\hline Extra Professional Development & 3 & 60 \\
Additional Individual Training & 5 & 100 \\
Additional Resources (Shadowing/Modeling/Role Playing) & 2 & 40 \\
Training for Para-Professional/CLASS Peer Model Observations & 1 & 20 \\
\hline
\end{tabular}

(87\%) always or sometimes refer to the Dimensions Guide of the CLASS, with $13 \%$ never referring to it despite the importance of referencing the Dimensions Guide in ensuring the fidelity of the instrument. The guide is an important element of implementation, as it is intended to provide daily support to teachers through examples and intentional planning. This process of honing one's skills supports sound teaching practices and ultimately produces higher student outcomes. With only $7 \%$ of the teachers "always" referring to the Dimensions Guide, the question arises as to how valid the outcomes obtained are for the remaining $93 \%$ of classrooms.

With regard to the survey results on perceptions of support, $40 \%$ of teachers feel that they are well supported in the implementation of CLASS. A majority of the respondents $(60 \%)$ do not feel they receive adequate support or are unsure whether the support received is adequate. This percentage gives the authors pause, since conclusions regarding the outcomes of CLASS cannot be drawn if the majority of the surveyed teachers implementing this instrument do not receive, or are unsure whether they receive, adequate support for implementation.

When asked to self-identify the domain in which they needed the most improvement, $86.7 \%$ of participants felt they required additional support regarding Instructional Support. The majority of teachers surveyed actively identified Instructional Support (analysis and reasoning, brainstorming, higher order thinking, expansion of information, language modeling) as the domain in which they require the most support. This domain comprises the majority of whole group instruction and a significant portion of the school day and is basic to supporting strong student-teacher dialogue. Further, this area promotes skill development in domains that students would be required to further enhance within each grade level.

Focus group responses echoed the same themes, as respondents indicated that more support is needed specifically with regard to increasing positive interactions and conversations, understanding the domain of Instructional Support, and incorporating more CLASS tool ideas in the curriculum. The biggest issue that the focus group unanimously faces is that the CLASS tool does not align with different aspects of the day that are required for fidelity in implementing the curriculum. This lack of alignment creates a disconnection between what is actually happening in the classroom and the evaluation instrument. Another area where focus group teachers feel they need support is in facilitating in-depth conversations with students to build on relationships and interactions. Focus 
group teachers' comments overlapped with the survey results in that they indicated that professional development needs to include role playing, shadowing teachers, and peer-modeling and walk-throughs, as well as individual coaching in identified areas of concern on personal CLASS evaluations.

\section{Limitations}

This study had several limitations. Even with a 50\% response rate, a larger response could have been achieved if the survey had been sent to all pre-kindergarten teachers in the district. This may have also increased the interest in focus group participation. In addition, the survey was not based on existing survey tools and questions were designed as a cursory dive into perceptions. Future survey tools will contain consistent formatting in terms of Likert indicators and in short answer prompts. Another limitation is that the focus group did not meet in person due to scheduling constraints. Interpersonal dialogue may have prompted different responses or ideas. A final limitation of this study is that support to CLASS varies across the district. The district selected for this study has multiple support systems in place for CLASS training. Results would vary in districts without these systematic supports.

\section{Practical Application of Research}

The outcomes of this study could guide school district supervisors in understanding the need for further professional development opportunities within areas relevant to the needs of prekindergarten teachers. As the CLASS assessment tool is widely implemented within diverse pre-kindergarten classrooms, teachers desire effective training in the areas upon which they are being evaluated. Providing these professional development opportunities, that are specific to areas of self-identified needs, will further enhance morale and confidence among teachers in their ability to provide developmentally appropriate guidance to their students.

\section{Implications for Future Research}

This study prompts future examination of teachers' perceived sense of efficacy and confidence in implementation of CLASS. Confidence and a sense of mastery in the classroom lead to validity in implementation of curricula and assessments. Through this research, the authors learned that while the majority of teachers surveyed felt confident in implementing CLASS, only a very low percentage (7\%) indicated that they referenced the packaged handbook for the assessment (Dimensions Guide) on a daily basis. The comparisons made in Figure 1 prompt the authors to consider future research as $7 \%$ of teachers reported feeling "very confident" in their implementation of CLASS and 7\% of teachers indicated that they "always" utilize the CLASS Dimensions Guide. Twenty percent of teachers reported lack of confidence in implementing CLASS with $13 \%$ of teachers "never" utilizing the Dimensions Guide). As the results of the survey are 
anonymous, the authors are not able to attribute specific responses to individual participants but examining feelings of confidence in relation to daily utilization of the Dimensions Guide is the foundation for future inquiry.

In the focus group, a teacher stated that she is a hands-on learner who would prefer individual coaching, walk-throughs, and modeling to improve practices, rather than a written document. Given the dearth of research examining teachers' perception of their personal performance in implementing CLASS, the authors feel it essential to bridge that gap through future studies. Systematically providing in-depth training through mentors, class walk-throughs, and role playing may significantly impact a teacher's confidence and understanding of CLASS. The authors wish to collect more data on individual CLASS scores prior to and following sustained professional development efforts offered through various interpersonal modes. Evaluating the impact on different types of supports (individual coaching, training for paras, walkthroughs, etc.) on CLASS scores over various durations of time will permit recommendations to be made to school districts and education providers. This study indicates that teachers are aware of their deficits and are interested in receiving support in the area of CLASS implementation, providing the authors with a rich opportunity to implement classroom action research.

\section{Conclusion}

The CLASS tool is a measure of teacher-child interactions in an early childhood classroom setting and has become a widely utilized means of evaluation. Building positive and impactful interactions with students can help improve students' academic and social skills. To facilitate those positive outcomes, teachers need to feel confident and well supported in their implementation of the instrument. This study is a preliminary step in seeking inputs from the teachers themselves on how classroom performance and evaluation scores can be improved, to ultimately support strong student outcomes.

\section{Conflicts of Interest}

The authors declare no conflicts of interest regarding the publication of this paper.

\section{References}

Allar, I., Jones, E., \& Bulger, S. (2018). Using I Am Moving, I Am Learning to Increase Quality Instruction in Head Start Classrooms. Early Childhood Education Journal, 46, 93-102. https://doi.org/10.1007/s10643-017-0843-0

Connors-Tadros, L., \& Hororwitz, M. (2014). How Are Early Childhood Teachers Faring in State Teacher Evaluation Systems? CEELO Policy Report, Center on Enhancing Early Learning Outcomes.

Hambre, B., Goffin, S., \& Kraft-Sayre, M. (2009). Classroom Assessment Scoring System (CLASS): Implementation Guide.

https://www.vbgrowsmart.com/providers/Documents/CLASSImplementationGuide.pdf 
Hamre, B. K., Pianta, R., Downer, J. T., DeCoster, J., Mashburn, A. J., Jones, S. M., Brown, J. L., Cappella, E., Atkins, M., Rivers, S. E., Brackett, M. A., \& Hamagami, A. (2013). Teaching through Interactions: Testing a Developmental Framework of Teacher Effectiveness in over 4,000 Classrooms. The Elementary School Journal, 113, 461-487. https://doi.org/10.1086/669616

La Paro, K. M., Williamson, A. C., \& Hatfield, B. (2014). Assessing Quality in Toddler Classrooms Using the CLASS-Toddler and the ITERS-R. Early Education and Development, 25, 875-893. https://doi.org/10.1080/10409289.2014.883586

Martella, J., \& Connors-Tadros, L. (2014). Center on Great Teachers and Leaders at American Institutes for $R$.

Mashburn, A. J., Pianta, R. C., Hamre, B. K., Downer, J. T., Barbarin, O. A., Bryant, D., Howes, C. et al. (2008). Measures of Classroom Quality in Prekindergarten and Children's Development of Academic, Language, and Social Skills. Child Development, 79, 732-749. https://doi.org/10.1111/j.1467-8624.2008.01154.x

Pianta, R. C., La Paro, K. M., \& Hamre, B. K. (2008). Classroom Assessment Scoring System (CLASS) Manual, Pre-K. Baltimore, MD: Paul H. Brookes Pub. Co.

Reinking, K. A. (2015). Early Childhood Teacher Assessment: Observation, Feedback, and Self-Assessment. Current Issues in Education, 18. https://cie.asu.edu/ojs/index.php/cieatasu/article/view/1362

Gaches, S., \& Hill, D. (2017) Power and Assessment: A Genealogical Analysis of the CLASS. Journal of Curriculum and Pedagogy, 14, 125-142. https://doi.org/10.1080/15505170.2017.1335253

Downer, J. T., Booren, L. M., Lima, O. K., Luckner, A. E., \& Pianta, R. C. (2010). The Individualized Classroom Assessment Scoring System (in CLASS): Preliminary Reliability and Validity of a System for Observing Preschoolers' Competence in Classroom Interactions. Early Childhood Research Quarterly, 25, 1-16. 


\section{Appendix A. Survey on CLASS}

Master Class Survey

${ }^{*}$ Required

1) How confident are you with the CLASS tool? *

Mark only one oval.

- Very confident

- Somewhat confident

- Not so confident

- Not at all confident

2) How often do you refer to the Dimension Guide? *

Mark only one oval.

- Always

- Sometimes

- Never

3) How do you utilize the Dimension Guide? *

4) In which domain do you feel you need the most improvement? *

Mark only one oval.

- Emotional Support

- Classroom Organization

- Instructional Support

5) Do you feel you receive enough support to improve your teaching practices using CLASS? *

Mark only one oval.

- Yes

- No

- Unsure

6) What types of support do you feel would benefit you to help you understand and use the CLASS tool? *

Mark only one oval.

- Extra professional development

- Additional individual training in improvement areas

- Additional resources

- Other:

7) Additional comments if any: 